\begin{tabular}{|c|ccc|}
\hline & PORT SAID ENGINEERING RESEARCH JOURNAL \\
\hline
\end{tabular}

\title{
Feasibility Analysis for Power Transformer Expectancy and Loss of Life "A practical Case Study in Egyptian Electricity Transmission Company"
}

\author{
I. M. Henidaq ${ }^{\text {, G. A. Mahmoud }}{ }^{2}$, A. A. Daoud ${ }^{3}$ and H. E. Zarzoura ${ }^{4}$
}

\begin{abstract}
Quality of power supply is now a major worldwide important is sue making harmonic analysis an essential element in power system planning and design. Because of the power transformers are major components in power systems; this paper studies the impact of power harmonics on power transformer. This phenomenon increases the power losses, over loading, over voltage conditions; accelerate aging of life and failure probability of transformer. The paper refers to the importance of mitigation this phenomenon, and presents a typical case study of high voltage power transformer which exists in Egyptian Electricity Transmission Company (EETC). The electrical power network is simulated using the ETAP 6.0.0, and the results demonstrate the importance of mitigation of this phenomenon.
\end{abstract}

Keywords: Harmonic, Nonlinear load, Total Harmonic Distortion (THD)

\section{Introduction}

Traditional electrical system design had very little needs to deal with harmonics because the loads typically designed were linear in nature. In many cases a major portion of the loads today are nonlinear in nature, the loading due to harmonics created by these loads must also be taken into consideration [1].

Harmonics are integral multiples of some fundamental frequency that, when added together, result in a distorted waveform [2]. Non-linear equipment or components in the power system cause distortion of the current and extent of the voltage. These sources of distortion can be divided into three groups; loads, the power system itself (HVDC, SVC, transformers, etc.) and the generation (synchronous generators). The dominating distortionproducing group, globally, are the loads. At some locations HVDC-links, SVC's, arc furnaces and wind turbines contributes more than the other sources. The generation can, during some special conditions, contribute to some voltage distortion at high voltage transmission level. The characteristic of non-linear loads is that they draw a distorted current waveform even though the supply voltage is sinusoidal.

The influence of voltage and current harmonics as harmful effects upon all power components, these harmonics might cause a protection relay to fail to trip under fault conditions, or cause mal-trip when no fault exists [3].

Harmonics have significant effect on power transformer; non-sinusoidal currents generate extra losses heating of the conductors, enclosures, clamps, bolts etc. Thus reducing the efficiency of the transformer and reduction in expected life span of a distribution transformer. An additional effects of harmonics in the network is possible oscillations between the transformer and line capacitances or any installed capacitors [4],

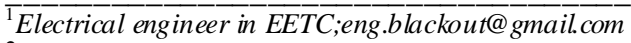

${ }^{2}$ Department of Electrical Engineering, Faculty of Engineering, Port Said University,Egypt; gamalagag@hotmail.com

3 Department of Electrical Engineering, Faculty of Engineering, Port Said University, Egypt; Ahmed.ali.daoud@ gmail.com

${ }^{4}$ Technical consultant in EETC; hamed_zarzoura@hotmail.com
}

accelerating the loss of life of the insulation due to the additional heating of the windings. This will lead to a which known as system natural resonance phenomenon.

So, the large and hazard amount effects of power harmonics on power system generally, makes detection and following mitigation methods of power harmonics as obligated choice to improve the power quality of the power system with preserving the security, dependability and reliability. From other hand keeping low THD (Total Harmonic Distortion) values on a system will further ensure proper operation of equipment and a longer equipment life span.

In this paper the study of the effect of harmonics on power transformer operation is illustrated using a network of power system taken from Ref [5]. The harmonics study is simulated with adding two buses with two transformers $230 / 66 \mathrm{KV}$ and $66 / 11 \mathrm{KV}$ respectively (as shown in the enclosed circle) feed ing a load of source harmonics using as shown in Fig.1. The study illustrates that, the effects of power harmonics not only contribute to emerging over load conditions, "therefore over load occurs in assistant switch gear of power transformer as circuit breakers, current transformers, capacitor banks and ...etc." but also contribute to emerging over voltage conditions. The presence of harmonic makes a massive increase in the reactive power, apparent power and decrease the active power compared with the same load in normal case.

This analysis gives conclusive evidence for harmonic role in reducing the expectancy of life and increasing of loss of life of power transformer.

The paper is organized as follows: Section 2 demonstrates the general and theoretical concepts to determine those effects on power system components (especially on power transformer). Section 3 presents the results obtained from the case study. Finally section 4 discusses the conclusion of this work. 


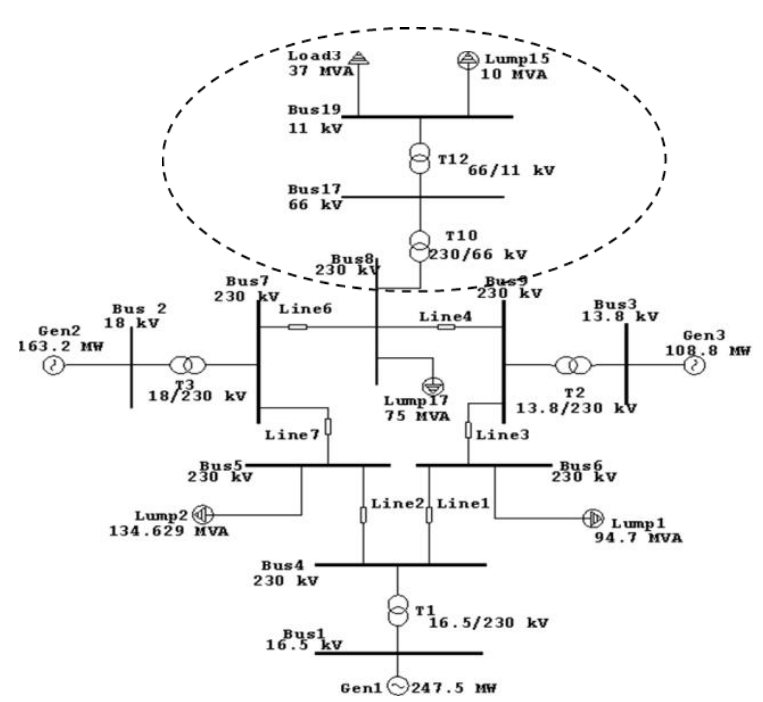

Figure 1: The single line diagram of the study system

\section{Effect of Harmonics on Power Transformer}

\subsection{Current Distortion \& Voltage Distortion}

The capacitance in farad of a capacitor bank at any voltage can be determined fro $m$ the next expression [6].

$$
C=\frac{Q_{C}(M V A R)}{2 * \pi * f * V_{L}^{2}(K V)}
$$

Where,

\section{$C$ : Capacitance in $\mathrm{F}$.}

$Q_{C}$ : Reactive power in MVAR.

$V_{L}$ : Line voltage in $\mathrm{KV}$.

$f$. Operating frequency in $\mathrm{HZ}$.

The approximate form for true power factor in nonsinusoidal situations can be calculated as the following [7]:

$$
P . F=\frac{1}{\sqrt{1+\left(T H D_{I} / 100\right)^{2}}}
$$

Where,

$T H D_{I}$ : Total harmonic distortion of current, is given by [8].

$$
T H D_{I}=\frac{\sqrt{\sum_{h}^{\infty} I_{h, r m s}^{2}}}{I_{r m s}} * 100 \%
$$

Where $I_{\text {h.rms }}$ is amplitude of the harmonic current components of order of $\mathrm{h}$ (i.e. the $\mathrm{h}^{\text {th }}$ harmonic and $I_{r m s}$ is the rms values of all harmonics).

When harmonics are presented, voltages and currents may be represented for any bus as [9]:

$$
\begin{gathered}
I_{h}=I \sqrt{1+\left(\frac{T H D_{I}}{100}\right)^{2}} \\
V_{h}=V \sqrt{1+\left(\frac{T H D_{V}}{100}\right)^{2}}
\end{gathered}
$$

Where:

$I, V$ : Current or voltage for sinusoidal situation.
$I_{h}, V_{h}$ : Current or voltage for non-sinusoidal situation.

\subsection{Effect on Transformer Losses}

Transformer losses are categorized as: no-load loss (excitation loss); load loss (impedance loss) [10,11].

$$
P_{T . L}=P_{N L}+P_{L L}
$$

Where:

$P_{T L}$ : Total losses of power transformer in $\mathrm{KW}$.

$P_{N L}$ : No- losses of power transformer in KW.

$P_{L L}$ : Load losses of power transformer in $\mathrm{KW}$.

The excitation losses are known as no-load losses $P_{N L}$ which contains two components Hysteres is loss $P_{h}$ and Eddy current loss $P_{\text {E.C. }}$. The Hysteresis loss can be calculated from next equations $[12,13]$.

$$
P_{h}=K_{h} * B_{\max }^{1.6} * f
$$

Where,

$P_{h}:$ Hysteresis loss in KW.

$\mathrm{K}_{\mathrm{h}}$ : Hysteres is constant.

$B_{\text {max }}$ : Maximum flux density in web $/ \mathrm{m}^{2}$.

Hysteresis constant $K_{h}$ is a function of the material used for the core which equal $1.19 * 10^{2}$ according to power transformer specifications [14].

The transformers operation in non-sinusoidal conditions produces supplementary power losses in its components: windings and magnetic circuits, the magnitude of the ohmic losses increases with the square of the load current and are proportional to the resistance of the windings which can be calculated from [15]:

$$
P_{C . L, h}=P_{C . L}\left\lfloor l+\left(T H D_{I}\right)^{2}\right\rfloor
$$

Where,

$P_{C . L, h}$ : Copper losses with harmonics in KW.

The additional of hysteresis losses caused by harmonics $\Delta P_{h, H}$, is given by [16]:

$$
\Delta P_{h, H}=P_{h} *\left[\sum_{h=1}^{h=\max }\left(\frac{I_{h}}{I_{R}}\right)^{2} * h^{0.8}\right]
$$

Where:

$h$ : Harmonic order, 1, 2, 3, etc.

$I_{h}$ : Current at harmonic order $\mathrm{h}$ in amp.

$I_{R}$ : Rated current in amp.

And the additional eddy current losses caused by harmonics $\Delta P_{E . C, H}$, given by [17]:

$$
\Delta P_{E . C, H}=P_{E . C} *\left[\sum_{h=1}^{h=\max }\left(\frac{I_{h}}{I_{R}}\right)^{2} * h^{2}\right]
$$

\subsection{Loss of life}

The impact of harmonics on power transformer is losses increase and consequent by temperature rise.

The final top-oil rise of temperature for oil immersed transformer transient heating in relation to the ambient temperature can be calculated through the following expression $[18,19]$.

$$
\theta_{O F}=\theta_{01}\left[\frac{P_{\text {COPPER LOSSES } . H^{+}} P_{h, H}+P_{E . C, H}}{P_{\text {COPPER LOSSES }}+P_{h^{+}} P_{E . C}}\right]^{m_{1}}
$$

Where:

$\theta_{O F}$ : Final top-oil temperature rise in relation to the ambient temperature with non-linear load in $\left({ }^{\circ} \mathrm{C}\right)$. 
$\theta_{01}$ : Top-oil temperature rise in relation to the ambient temperature with linear load in $\left({ }^{\circ} \mathrm{C}\right)$.

$m_{l}$ : Coefficient varying from 0.8 to 1 , the lower limit applies to self-cooled transformers and the higher limit to forced-oil-cooled ones.

To reach the above final temperature, the transient behavior is described by equation (12).

$$
\theta_{0}=\theta_{0 F}\left(1-e^{-t / T_{0}}\right)+\theta_{i 0} e^{-t / T_{0}}
$$

Where:

$\theta_{0}$ : Instantaneous top-oil temperature rise in $\left({ }^{\circ} \mathrm{C}\right)$.

$T_{0}$ : Thermal oil time constant in (hour).

$\theta_{i 0}$ : Initial top-oil temperature rise in $\left({ }^{\circ} \mathrm{C}\right)$.

$t$ : Time in (hour).

The final temperature rise at the transformer winding hottest-spot can be estimated by equation (13). This equation defines the temperature rise in relation to the final top-oil temperature:

$$
\theta_{e f}=\theta_{e 1}\left[\frac{P_{\text {COPPER LOSSES.H }}}{P_{\text {COPPER LOSSES }}}\right]^{m_{2}}
$$

Where,

$\theta_{e f}$ : Winding temperature rise with non-linear load in $\left({ }^{\circ} \mathrm{C}\right)$.

$\theta e_{1}$ : Winding temperature rise with linear load in $\left({ }^{\circ} \mathrm{C}\right)$.

$m_{2}$ : Practical coefficient varying from 0.8 to 1 , the lower limit applied to for self-cooled transformers and the higher limit for forced-oil-cooled ones.

The corresponding winding temperature transient is described by equation (14):

$$
\theta_{e}=\theta_{e f}\left(1-e^{-t / T_{e}}\right)+\theta_{i e} e^{-t / T_{e}}
$$

Where:

$\theta_{e}$ : Instantaneous winding temperature rise in $\left({ }^{\circ} \mathrm{C}\right)$.

$\theta_{i e}$ : In itial winding temperature rise in $\left({ }^{\circ} \mathrm{C}\right)$.

$T_{e}$ : Thermal winding time constant in (hour).

The hottest-spot temperature can be calculated from next equation:

$$
\theta_{m Q}=\theta_{a}+\theta_{O F}+\theta_{e f}
$$

Where,

$\theta_{m Q}:$ Hottest-spot temperature in $\left({ }^{\circ} \mathrm{C}\right)$.

$\theta_{a}$ : A mbient temperature in $\left({ }^{\circ} \mathrm{C}\right)$.

The instantaneous hottest-spot temperature can be calculated from the following equation, as given in [20]:

$$
\theta_{m}=\theta_{a}+\theta_{0}+\theta_{e}
$$

The life reduction and real life of transformer can be expressed from the following equation, as given in [21]:

$$
\begin{aligned}
& \text { Life }(\mathrm{pu})=9.8 * 10^{-18} * e^{\left(\frac{15000}{\theta_{m Q^{+273}}}\right)} \\
& \text { real life }=\text { life }(\mathrm{pu}) * \text { normal insulation life }
\end{aligned}
$$

The aging acceleration factor for a given load and temperature or for a changing load and temperature profile is given from the following equation.

$$
F_{A A}=e^{\left(\frac{15000}{\theta_{m Q, R}}-\frac{15000}{\theta_{m Q}}\right)}
$$

Where:

$F_{A A}$ : Aging acceleration factor.

$\theta_{m Q, R}:$ The winding hottest-s pot temperature at rated load in $\left({ }^{\circ} \mathrm{C}\right)$.

Due to that the insulation aging is accumulative process, thus the equivalent aging acceleration factor can be expressed as:

$$
F_{E Q A}=\frac{\sum_{n=1}^{N} F_{A A} \Delta t_{N}}{\sum_{n=1}^{N} \Delta t_{N}}
$$

Where:

$F_{E Q A}$ : Equivalent aging factor for total time period,

$n$ : the inde $\mathrm{x}$ of time interval, $t$.

$N$ : the total number of time intervals.

$F_{A A n}$ : The aging acceleration factor for the temperature which exists during the time interval $\Delta t_{n}$.

The equivalent loss of life in total time period is determined by multiplying the equivalent aging by time period (t) in hours. Usually the total time period used is 24 hours. Therefore the equation of percent los s of life is as follows [22].

$$
\% \text { Loss of life }=\frac{F_{E Q A} * t * 100}{\text { normal insulation life }}
$$

\section{Case Study}

\subsection{Problem}

The problem was started in a certain sub-station of E.E.T.C which supplies power to industrial loads. The scenario of the problem initiation was divided into four stages. The first one, that the power transformer was tripped - four times or more - by differential relay. The second stage, that explosion of power transformer was occurred. The third stage is the replacement of the old transformer with new one. And the fourth stage, that the new power transformer was tripped again by differential relay. At every trip, all routine site tests on power transformer (INSULATION TESTS, TURNS RATIO, D.C RESISTANCE) were passed, "these testes are proceeded upon power transformer periodically and in case of tripping the power transformer by a mechanical or electrical protection systems". So that research tried to acquaint with all reasons of this problem.

Using the model of Ref. [5], the model is successfully validated by ETAP 6.0.0 software as shown in fig. 1 .

The main two reasons for using the model of Ref. [5], the first one, the case study part of EETC network is approximately similar than the model of Ref. [5], the second reason, to build this research upon a clear scientific base as used in the model of Ref. [5]. 
The network is the same of validation case but with some additions like as: two step-down power transformers, current transformers, voltage transformers, measurement devices, circuit breakers, static load and lu mp load which act as industrial loads, these additions are compatible with the real network.

The main element of this study is $T 12$; this power transformer has the same specification of EETC's power transformer and faced the same load as illustrated in table 1. The measured values of power harmonics in EETC's power transformer are the same values which simulated on $T 12$.

Table 1: The power transfor mer (T12) specifications

\begin{tabular}{|c|c|c|c|}
\hline $\mathrm{S}$ & Quantity & Value & Unit \\
\hline 1 & Rated power & 40 & MVA \\
\hline 2 & Rated frequency & 50 & $\mathrm{~Hz}$ \\
\hline 3 & Primary voltage & 66000 & $\mathrm{~V}$ \\
\hline 4 & Secondary volt age & 11000 & $\mathrm{~V}$ \\
\hline 5 & Rated primary current & 349.91 & AMP \\
\hline 6 & Rated secondary current & 2099.46 & AMP \\
\hline 7 & No. of primary turns & 1200 & Turns \\
\hline 8 & No. of secondary turns & 200 & Turns \\
\hline 9 & Primary winding resistance & 0.3365 & $\Omega$ \\
\hline 10 & $\begin{array}{l}\text { Secondary winding } \\
\text { resistance }\end{array}$ & 0.00831 & $\Omega$ \\
\hline 11 & Connection & Dyn 11 & --- \\
\hline 12 & Temperat ure rise of coil & 65 & $\mathrm{C}$ \\
\hline 13 & Total full load losses & 167 & $\overline{K . W}$ \\
\hline 14 & Impedance & 12.5 & $\%$ \\
\hline 15 & Core cross section diameter & 560 & $\mathrm{~m} \cdot \mathrm{m}$ \\
\hline 16 & Cooling mode & ONAF & --- \\
\hline 17 & Ambient temperature & 30 & ${ }^{\circ} \mathrm{C}$ \\
\hline 18 & Top oil rise over ambient & 45 & ${ }^{\circ} \mathrm{C}$ \\
\hline 19 & Hot spot factor & 1.3 & --- \\
\hline 20 & $\begin{array}{l}\text { Rated circuit breaker current } \\
\text { of primary side }\end{array}$ & 600 & AMP \\
\hline 21 & $\begin{array}{l}\text { Rated circuit breaker current } \\
\text { of secondary side }\end{array}$ & 2500 & AMP \\
\hline
\end{tabular}

\subsection{System Modeling}

\subsubsection{Normal Condition}

Bus19 which connected to $T 12$ in the network had a poor power factor $(77 \%)$, so the need to correct this poor power factor was very necessary. T12 connected with 36.19 M.W, the actual power factor is $(77 \%)$ and the required is $(98 \%)$. The power of the capacitor bank Qc can be obtained from known equation.

The capacitance current reflects, the circuit breaker rating current of capacitor should not be less than 2500 amp.

Fig. 2 shows the specific part of study, which shows the load flow and losses of power transformer $T 12$ by ETAP 6.0.0 software. Table 2 reviews the simulation result of load flow for BUS 17, BUS 19 and capacitor bank. Table 3 reviews the power transformer $T 12$ loading and losses.

Fig. 3 is considered as conclusive evidence of that BUS 17 and 19 have a pure wave form without harmonic spectrums.

The simulation didn`t appear any critical or marg inal alarms of this specific part.

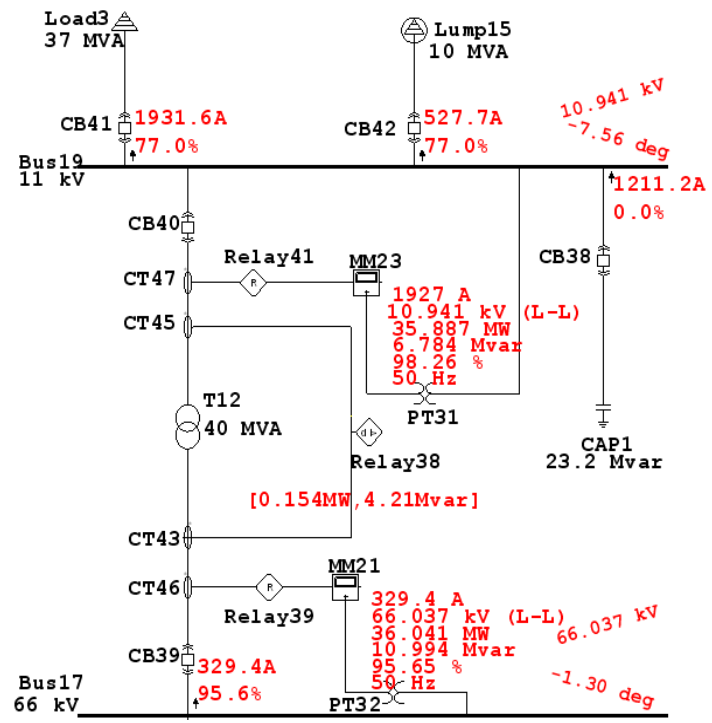

Figure 2: The single line diagram

Table 2: The load fl ow results

\begin{tabular}{|c|c|c|c|c|}
\hline De vice ID, & \multicolumn{4}{|c|}{ Load Flow } \\
\hline$\#$ & MW & MVAR & AMP. & \% P.F \\
\hline BUS 17 & 36.041 & 10.994 & 329.4 & 95.6 \\
\hline BUS 19 & 35.887 & 6.784 & 1927.2 & 98.2 \\
\hline$C 1$ & ---- & 23.2 & 1211.2 & --- \\
\hline$X C 1$ & \multicolumn{4}{|c|}{$5.22 \Omega$} \\
\hline$C$ & \multicolumn{5}{|c|}{$610.3 \mu F$} \\
\hline
\end{tabular}

*Where $C 1$ is a capacitor bank which installed on $B U S 19$ to improve the power factor.

Table 3: (T12) loading and losses

\begin{tabular}{|c|c|c|c|c|c|}
\hline \multirow{2}{*}{ T } & \multirow{2}{*}{ Capability } & \multicolumn{2}{|c|}{ Loading } & \multicolumn{2}{c|}{ Losses } \\
\cline { 3 - 6 } & MVA & MVA & $\%$ & MW & MVAR \\
\hline$T 12$ & 40.000 & 37.681 & 94.2 & 0.154 & 4.21 \\
\hline
\end{tabular}

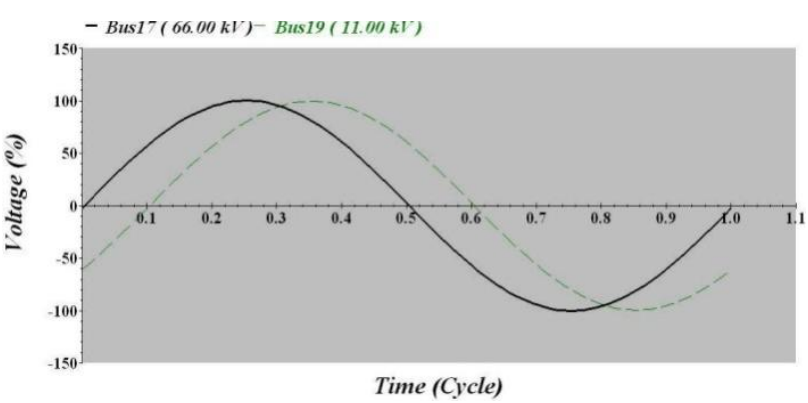

Figure 3: The vol tage wave form of BUS 17 and 19

The calculation is emphasis method to as sure of ETAP 6.0.0 software simu lation results.

The secondary current $I_{B}$ of power transformer $T 12$ and the secondary reactive power $\mathrm{Q}_{\mathrm{B}}$ can be calculated from known power equations.

Table 4 reviews the calculations result of load flow for BUS 17, BUS 19 and capacitor bank. From equations (6) and (7) table 5 reviews the calculations of power transformer $T 12$ loading and losses. 
Table 4: The load flow result

\begin{tabular}{|c|c|c|c|c|}
\hline \multirow{2}{*}{ De vice ID, } & \multicolumn{4}{|c|}{ Load Flow } \\
\hline$\#$ & MW & MVAR & AMP. & $\%$ P.F \\
\hline BUS 17 & 36.336 & 11.08 & 332.13 & 95.6 \\
\hline BUS 19 & 36.19 & 6.98 & 1944.93 & 98.19 \\
\hline$C 1$ & ---- & 23.0 & 1207.19 & --- \\
\hline$X C 1$ & \multicolumn{5}{|c|}{$5.26 \Omega$} \\
\hline$C$ & \multicolumn{5}{|c|}{$605.05 \mu F$} \\
\hline
\end{tabular}

Table 5: (T12) loading and losses

\begin{tabular}{|c|c|c|c|c|c|}
\hline \multirow{2}{*}{$\begin{array}{c}\text { T } \\
\text { ID. }\end{array}$} & \multirow{2}{*}{$\begin{array}{c}\text { Capability } \\
\text { MVA }\end{array}$} & \multicolumn{2}{|c|}{ Loading } & \multicolumn{2}{c|}{ Losses } \\
\cline { 3 - 6 } & & MVA & $\%$ & MW & MVAR \\
\hline$T 12$ & 40.000 & 37.99 & 94.97 & 0.146 & 4.11 \\
\hline
\end{tabular}

The previous calculations showed that the power transformer $T 12$ operated without over loading condition. On other hand the loading of power transformer not only didn't have affect on the primary and secondary circuit breaker rating of power transformer, but also didn't have any affect on capacitor bank's circuit breaker rating.

So, we have normal condition without any alarms.

\subsubsection{Abnormal Condition}

The importance of knowing the type of power harmonics in our industrial zone plant is not less than the importance of knowing the impact of this power harmonic. The analysis which achieved by E.E.T.C, made clear that the type of harmonic is PWM ASD (pulse width modulation, adjustable speed drives). This type of load (ASD) is used in the industry for controlling the speed of induction motors. Table 6 shows the total harmonic distortion of current (T.H. $\left.D_{I}\right)$ and voltage (T.H. $D_{V}$ ) on BUS 17, BUS 19 and C1.

Table 6: (T12) The total harmonic distortion

\begin{tabular}{|c|c|c|}
\hline De vice ID & T.H.D. $\%$ & T.H.D. \\
\hline$B U S 17$ & 53.65 & 16.625 \\
\hline$B U S 19$ & 55.03 & 48.31 \\
\hline$C 1$ & 283.97 & --- \\
\hline
\end{tabular}

Fig. 4 shows the load flows and harmonic flows of our study part, Table 7 shows the ETAP simulation result of load flow for $B U S 17, B U S 19$ and $C 1$ and Table 8 shows critical alarms of the study part. In Fig. 5 shows that the appearance of harmonic spectrum into BUS 17 and $B U S 19$, definitely a distorted wave form of $B U S 17$ and BUS 19 is appeared in Fig. 6.

Table 7: The load flow results

\begin{tabular}{|c|c|c|}
\hline \multirow{2}{*}{ De vice ID } & \multicolumn{2}{|c|}{ Load Flow } \\
\cline { 2 - 3 } & AMP & Vol tage (KV) \\
\hline BUS 17 & 373.9 & 66.94 \\
\hline$B U S 19$ & 2199.76 & 12.15 \\
\hline$C 1$ & \multicolumn{2}{|c|}{3646.5} \\
\hline
\end{tabular}

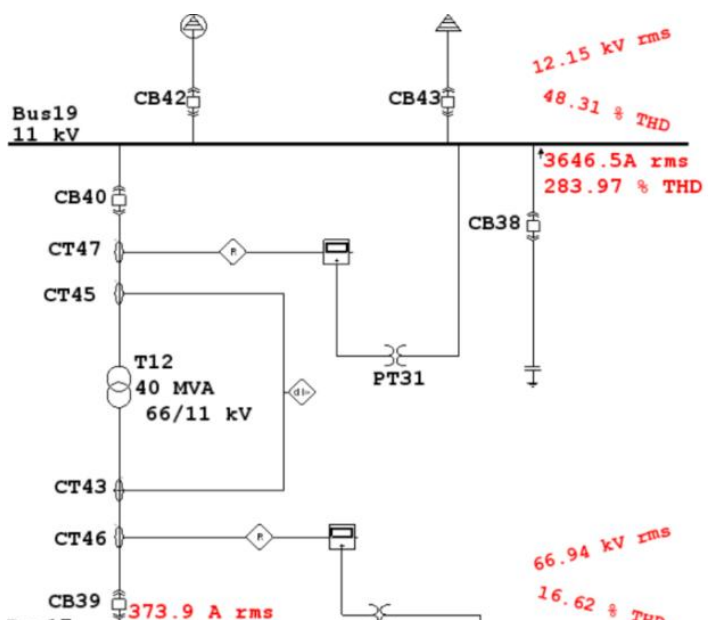

Figure 4: Harmonic fl ow and load flow

Table 8: The critical alarms

\begin{tabular}{|c|c|c|c|c|c|}
\hline & Condition & Operating & Unit & $\%$ & Harmonic \\
\hline $\begin{array}{c}B U S \\
17\end{array}$ & $\begin{array}{c}\text { Exceeds } \\
\text { limit }\end{array}$ & 53.65 & THD $_{\mathrm{I}}$ & 2146 & Total \\
\hline $\begin{array}{c}B U S \\
17\end{array}$ & $\begin{array}{c}\text { Exceeds } \\
\text { limit }\end{array}$ & 16.62 & THD $_{\mathrm{v}}$ & 664.8 & Total \\
\hline $\begin{array}{c}B U S \\
19\end{array}$ & $\begin{array}{c}\text { Exceeds } \\
\text { limit }\end{array}$ & 55.03 & $\mathrm{THD}_{\mathrm{I}}$ & 2201.2 & Total \\
\hline $\begin{array}{c}B U S \\
19\end{array}$ & $\begin{array}{c}\text { Exceeds } \\
\text { limit }\end{array}$ & 48.31 & $\mathrm{THD}_{\mathrm{v}}$ & 1932.4 & Total \\
\hline $\begin{array}{c}B U S \\
19\end{array}$ & $\begin{array}{c}\text { Over } \\
\text { voltage }\end{array}$ & 12.15 & $\mathrm{KV}$ & 110.45 & Total \\
\hline$T 12$ & Over load & 373.86 & $\mathrm{AMP}$ & 106.85 & Total \\
\hline$T 12$ & Over load & 2199.76 & $\mathrm{AMP}$ & 104.8 & Total \\
\hline$C 1$ & Over load & 3646.5 & $\mathrm{AMP}$ & 301.07 & Total \\
\hline
\end{tabular}

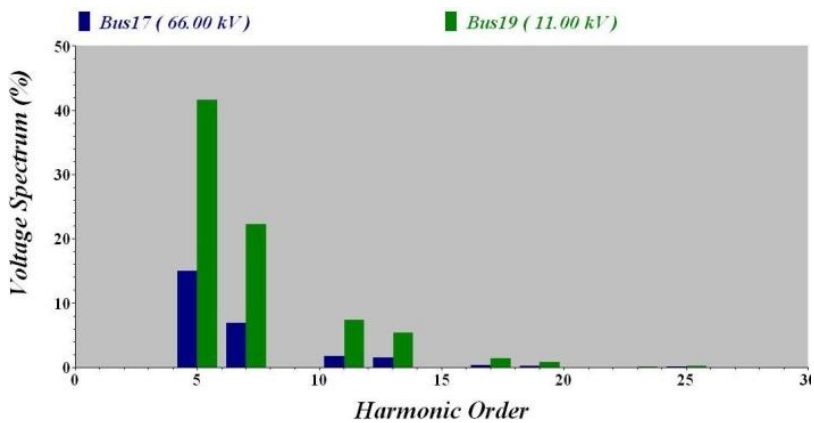

Figure 5: The har monic s pectrums of $B U S 17$ and 19

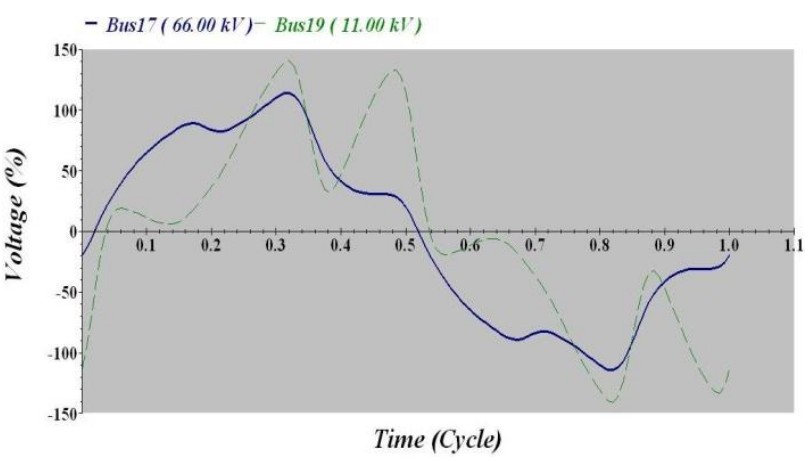

Figure 6: The vol tage waveform of $B$ US 17 and 19 
By ETAP 6.0.0 software simulation, the situation is very critical. The study part faced an abnormal and hazard condition.

The loading in MVA and losses are not applicable in ETAP 6.0.0 software harmonic module, but the calculation will proof that it is compatible with simulation, so it can be depended on the calculation in this point. From equations (4) to (10) table 9 reviews the calculation result of load flow for $B U S 17, B U S 19$ and capacitor bank. Table 10 reviews the power transformer T12 loading and losses.

Table 9: The load flow result

\begin{tabular}{|c|c|c|c|c|}
\hline De vice ID, & \multicolumn{4}{|c|}{ Load Flow } \\
\hline$\#$ & MW & MVAR & AMP. & Voltage(KV) \\
\hline BUS 17 & 30.3 & -31.492 & 376.91 & 66.943 \\
\hline$B U S 19$ & 30.050 & -35.8 & 2219.97 & 12.151 \\
\hline$C 1$ & ---- & 73.7 & 3634.4 & --- \\
\hline$X C 1$ & \multicolumn{5}{|c|}{$2 \Omega$} \\
\hline$C$ & \multicolumn{5}{|c|}{$1590 \mu F$} \\
\hline
\end{tabular}

Table 10: (T12) loading and losses

\begin{tabular}{|c|c|c|c|c|c|}
\hline \multirow{2}{*}{ T } & \multirow{2}{*}{ Capability } & \multicolumn{2}{|c|}{ Loading } & \multicolumn{2}{c|}{ Losses } \\
\cline { 3 - 6 } ID. & MVA & MVA & $\%$ & MW & MVAR \\
\hline$T 12$ & 40.000 & 43.7 & 109.25 & 0.250 & 4.31 \\
\hline
\end{tabular}

The previous calculations showed that how harmonics affect in the power transformer. These calculations have many serious points. The first one, the power transformer $T 12$ operated with over loading condition at the same connecting load, the total loading of $T 12$ becomes (43.70 MVA) which acts as (109.25\%) of power transformer capacity, this mean increasing by $(14.28 \%)$ of normal case. Second, the remarkable increases of losses inside the power transformer. Third, the effects of harmonic on capacitor bank, makes the load presented as a capacitive load. Fourth, the harmonics affect trended to poses a threat on capacity of capacitor bank's circuit breaker. Fifth, the effect of power harmonics takes the research to other side which can be known as over voltage state. The calculation showed that the voltage in BUS 17 is $(66.943 \mathrm{KV})$ which act as (101.43\%), this percentage is not dangerous in fact, but BUS 19 is $(12.151 \mathrm{KV})$ which act as $(110.46$ $\%$ ), indeed this percentage skipped the red line and it can be considered as very dangerous situation.

So, we have abnormal and hazard condition with alarms exists.

\subsubsection{Harmonic Mitigation}

One of the way out to resolve the is sue of harmonics would be using a suitable filters in the power system. Installing a filter for nonlinear loads connected in power system would help in reducing the harmonic effect. The filters are widely used for reduction of harmonics. With the increase of nonlinear loads in the power system, more and more filters are required.

Table 11 shows the simulation results of, the total harmonic distortion of (T.H.DI) and (T.H.D $)$ after installing a suitable filter.
Table 11: (T12) The total harmonic distortion

\begin{tabular}{|c|c|c|}
\hline Device ID, & T.H.D $\%$ & T.H.D \\
\hline BUS 17 & 16.26 & 6.68 \\
\hline BUS 19 & 16.67 & 24.63 \\
\hline
\end{tabular}

Fig. 7 shows that the load flows and harmonic flows of the part of study after fixing high-Pass filter, Table 12 shows the ETAP simulation result of load flow for $B U S$ 17 and BUS 19, and table 13 shows critical alarms of the study part. Fig. 8 shows that the appearance of harmonic spectrum into $B U S 17$ and $B U S 19$. A distorted wave form of BUS 17 and BUS 19 which shows in Fig. 9 appeared that the distortion still exists in wave form with a slightly smooth compares with a pervious harmonic case.

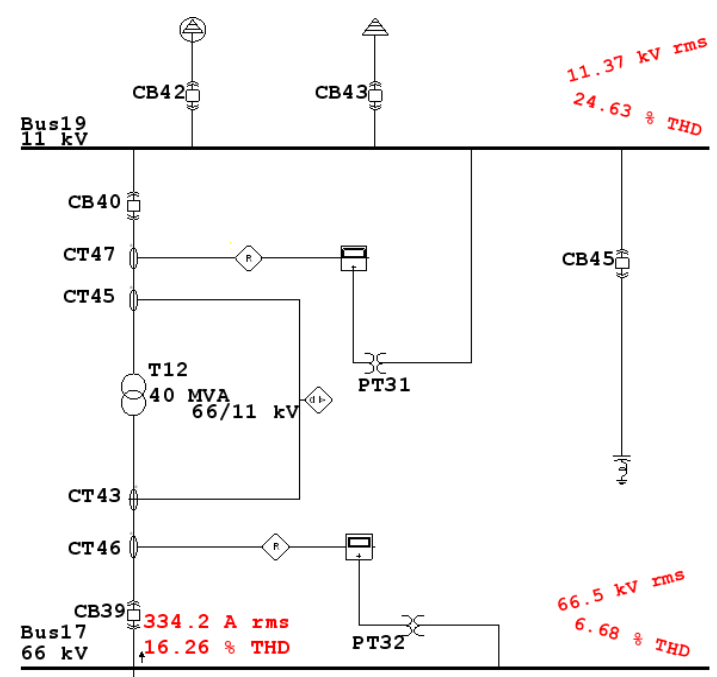

Figure 7: The harmonic flow and load flow

Table 12: The load flow result

\begin{tabular}{|c|c|c|}
\hline \multirow{2}{*}{ De vice ID, } & \multicolumn{2}{|c|}{ Load Flow } \\
\cline { 2 - 3 } & AMP & Voltage (KV) \\
\hline BUS 17 & 334.22 & 66.5 \\
\hline BUS 19 & 1956.49 & 11.37 \\
\hline
\end{tabular}

Table 13: The critical alarms

\begin{tabular}{|c|c|c|c|c|c|}
\hline De vice ID & Condition & Operating & Unit & $\%$ & $\begin{array}{c}\text { Harm } \\
\text { onic }\end{array}$ \\
\hline BUS 17 & $\begin{array}{c}\text { Exceeds } \\
\text { limit }\end{array}$ & 16.26 & $\mathrm{THD}_{\mathrm{I}}$ & 650.4 & Total \\
\hline BUS 17 & $\begin{array}{c}\text { Exceeds } \\
\text { limit }\end{array}$ & 6.68 & $\mathrm{THD}_{\mathrm{v}}$ & 267.2 & Total \\
\hline BUS 19 & $\begin{array}{c}\text { Exceeds } \\
\text { limit }\end{array}$ & 16.67 & $\mathrm{THD}_{\mathrm{I}}$ & 666.8 & Total \\
\hline BUS 19 & $\begin{array}{c}\text { Exceeds } \\
\text { limit }\end{array}$ & 24.63 & $\mathrm{THD}_{\mathrm{v}}$ & 985.2 & Total \\
\hline
\end{tabular}

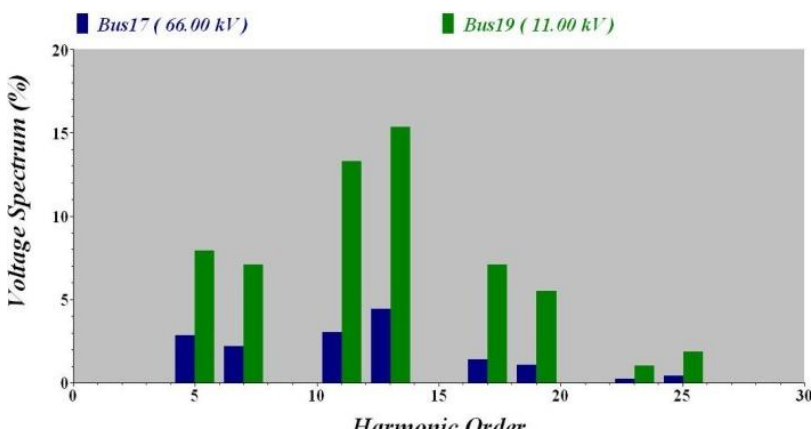

Figure 8: The harmonic s pectr ums of B US 17 and 19 


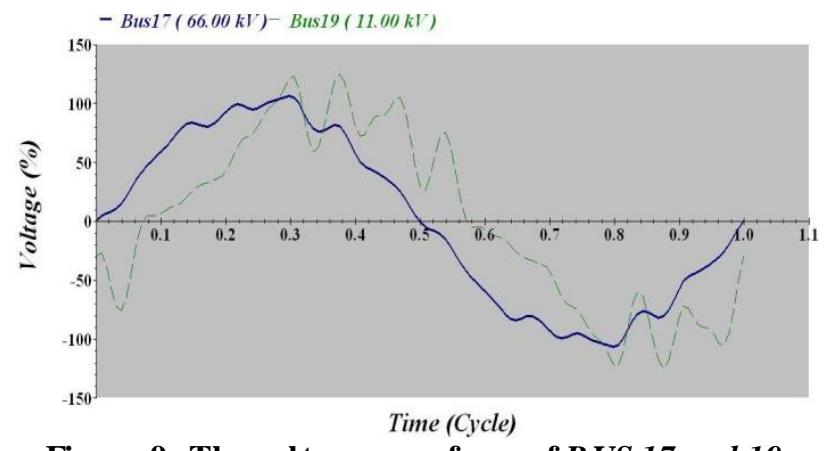

Figure 9: The vol tage waveform of $B$ US 17 and 19

The ETAP 6.0.0 software simulation proved that the filter mitigates harmonic, this mitigation is cleared in load flow, harmonic flow, harmonic spectrum, wave form of BUS 17 and BUS 19 and especially in critical alarms. All critical alarms are represented in exceeds limit of the (T.H. $\left.D_{I}\right)$ and (T.H.D $)$ which also decreased by adding the filter, with disappeared the over load and over voltage conditions. As usual in this paper, the calculation is an assure method of simulation method. So the current and voltage for BUS 17 and BUS 19 can determine from equations (4) and (5). The new P.F for BUS 17 and BUS 19 can be calculated from equation (2).

Also, the losses which include copper losses, hysteresis losses and eddy current losses can be estimated from equations (8), (9) and (10). Table 14 reviews the calculation result of load flow for BUS 17, BUS 19. Table 15 reviews the power transformer $T 12$ loading and losses.

Table 14: The load flow result

\begin{tabular}{|c|c|c|c|c|c|}
\hline \multirow{2}{*}{ De vice ID, } & \multicolumn{5}{|c|}{ Load Flow } \\
\cline { 2 - 6 } & MW & MVAR & AMP. & $\begin{array}{c}\text { VOLTAGE } \\
\text { (KV) }\end{array}$ & P.F \\
\hline BUS 17 & 36.25 & 13.5 & 336.50 & 66.18 & 0.94 \\
\hline BUS 19 & 36.08 & 9.24 & 1971.33 & 11.27 & 0.96 \\
\hline
\end{tabular}

Table 15: (T12) loading and losses

\begin{tabular}{|c|c|c|c|c|c|}
\hline \multirow{2}{*}{ T ID. } & \multirow{2}{*}{$\begin{array}{c}\text { Capability } \\
\text { MVA }\end{array}$} & \multicolumn{2}{|c|}{ Loading } & \multicolumn{2}{c|}{ Losses } \\
\cline { 3 - 6 } & & MVA & $\%$ & MW & MVAR \\
\hline$T 12$ & 40.000 & 38.68 & 96.7 & 0.1665 & 4.26 \\
\hline
\end{tabular}

The calculated results showed that how the filter mitigates harmonic affect in the power transformer.

These mitigations can be represented as the following necessary points. The first one, the over loading condition of power transformer T12 disappeared, the total loading of $T 12$ (38.68 MVA) which acts as (96.7\%) of power transformer capacity, this means the loading of power transformer increasing of normal case with $(2.5 \%)$ and decreasing of abnormal case with (12.55\%). Second, withdrawing the value of losses to $(114.0 \%)$ of $\mathrm{P}_{\mathrm{L}}$ and (103.6\%) of $\mathrm{Q}_{\mathrm{L}}$ compares with abnormal case which was $(171 \%)$ of $\mathrm{P}_{\mathrm{L}}$ and $(104.9 \%)$ of $\mathrm{Q}_{\mathrm{L}}$. Third, disappearing of over voltage conditions which can remark from that, the voltage of BUS 17 is $(66.18 \mathrm{KV})$ which acts (100.27\%) and the voltage of $B U S 19$ is $(11.27 \mathrm{KV})$ which acts $(102.45 \%)$. Fourth, the calculation showed also that no circuit breaker`s over loading condition exists. Fifth, the wave form becomes something better, bus still in distorted wave.
So, the filter makes the harmonic not poses a threat, this means no exists of serious conditions or critical alarms.

\subsection{The Loss of Life Before Harmonic Distortion}

The harmonics occurring in power systems result in additional losses in both transformer magnetic core and windings.

$\theta_{O F}$ of oil immersed transformer transient heating in relation to the ambient temperature can be calculated through equation (11), and $\theta_{0}$ can be calculated from equation (12).

The oil and winding thermal time constant of 2 and 0.5 hours will be taken respectively. Although several cases were studied, a single transient performance is given in Fig. 10. The result is associated to the transformer supplying a linear load during the period of time comprising $0 \leq \mathrm{t} \leq 14$ hours and a mixed composition (linear and non-linear load) during the interval of $14<\mathrm{t} \leq 24$ hours.

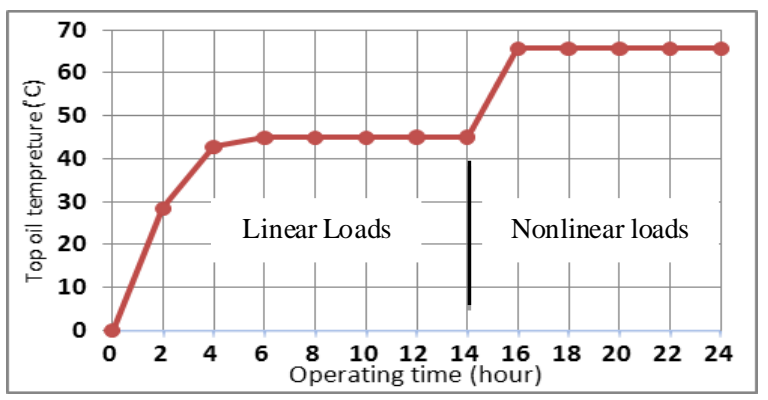

Figure 10: Instantane ous top-oil temperature rise versus time.

$\theta_{e f}$ and $\theta_{e}$ can be estimated from equations (13) and (14) respectively.

So, a single transient performance is given in Fig. 11.

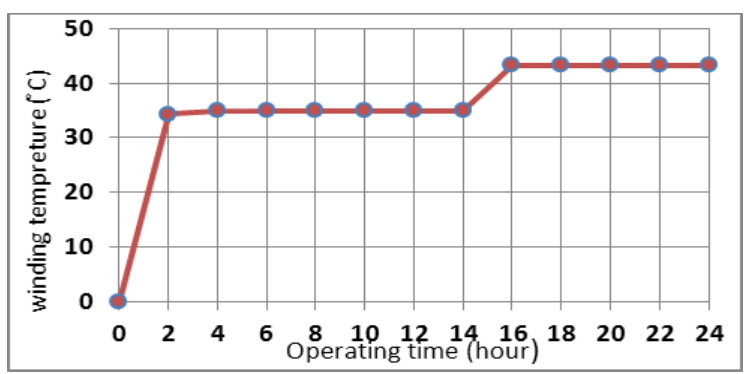

Figure 11: Instantane ous winding temperature rise versus time

$\theta_{m Q}$ can be calculated from equation (15), Fig. 12 shows the instantaneous hottest-spot temperature which calculated from equation (16). 


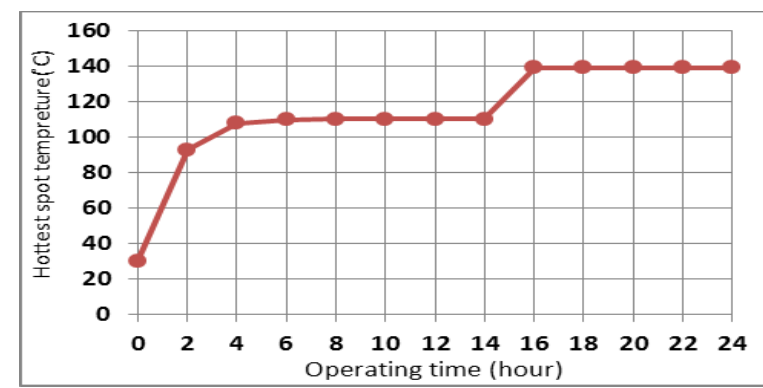

Figure 12: Instantane ous hot test-spot te mperature rise versus time

According to IEEE loading guide, the 180,000 hours or 20.55 years normal insulation life is suggested (24). After calculated hottest-spot temperature, the life reduction and real life of transformer can be expressed as equations (17) and (18).

\section{So, real life $=2.055$ years}

$F_{A A}$ for a given load and temperature or for a changing load and temperature profile over a 24 hours period, as equation (19), and the instantaneous aging acceleration factor can be noticed from Fig. 13, If $F_{A A}$ is appeared greater than 1, the hottest-spot temperature is greater than $110{ }^{\circ} \mathrm{C}$ (acceleration loss of life) and less than for temperature below $110{ }^{\circ} \mathrm{C}$ (extended life time) [23].

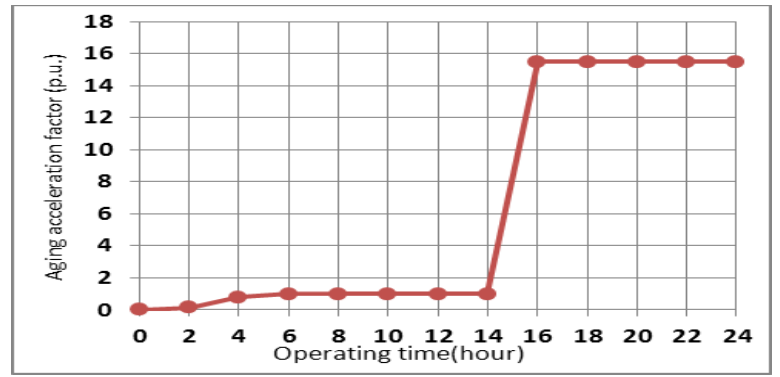

Figure 13: Instantane ous aging acceleration factor rise versus time

Due to insulation aging is accumulative process, thus the equivalent aging acceleration factor can be expressed as equation (20), and the equation (21) presents the percent loss of life.

The $0.1368 \%$ loss of life occurs per $2.74 * 10^{-3}$ years (24 hours), so the $100 \%$ loss of life will occur after 2.003 years. This result is assured of previous result which it is obtained from equations (17) and (18). Fig. 14 shows the $\%$ loss of life and \% expectancy of life for 24 hours.

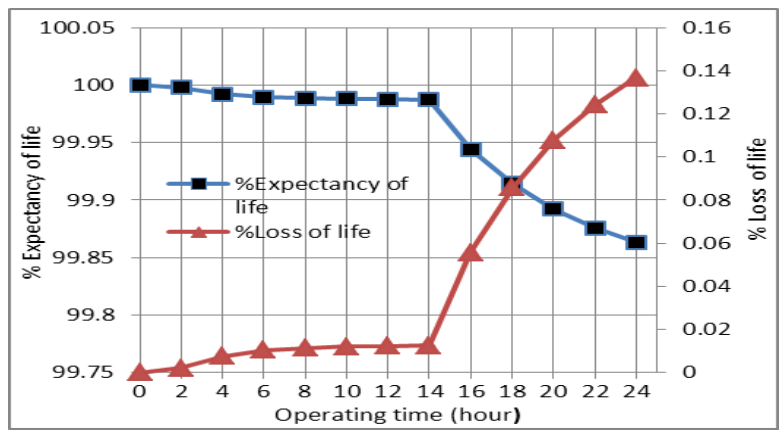

Figure 14: Instantane ous loss of life and expectancy of life versus time
The all effects of Harmonics in power system which discussed recently, explains the scenario of real status and shows the dangerous and hazard situation impacted on the power system.

\subsection{The Loss of Life After Harmonic Distortion}

While the harmonic mitigation method has active effects in power losses, over loading condition and ..., etc. The question now has this method an effect in loss of life of power transformer? So, to answer this question it should be resolve the equations of loss of life.

The final top-oil rise of temperature of oil immersed transformer transient heating in relation to the ambient temperature can be calculated through equation (11). But to reach the above final temperature, the transient behavior is described by equation (12).

The oil and winding thermal time constant of 2 and 0.5 hours will be taken respectively. Although several cases were studied, a single transient performance is given in Fig. 15. The result is associated to the transformer supplying a linear load during the period of time comprising $0 \leq \mathrm{t} \leq 14$ hours and a mixed composition (linear and non-linear load) during the interval of $14<\mathrm{t} \leq 24$ hours.

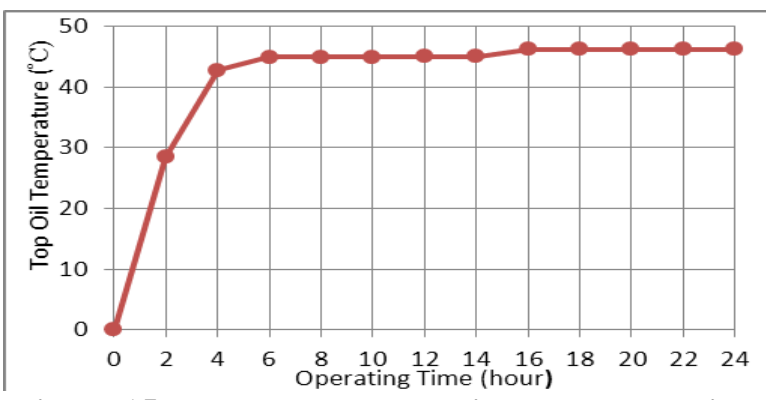

Figure 15: Instantane ous top-oil temperature rise versus time

The final temperature rise at the transformer winding hottest-spot which calculates the temperature rise in relation to the final top-oil temperature can be estimated by equation (13). The corresponding winding temperature transient is described by equation (14), so, a single transient performance is given in Fig. 16.

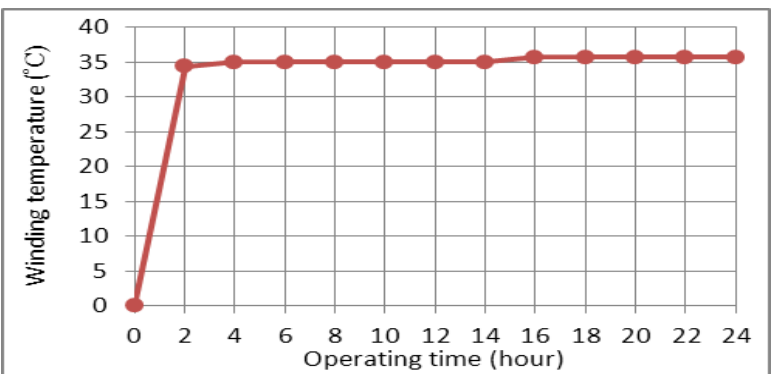

Figure 16: Instantane ous winding temperature rise versus time

Now, the hottest-spot temperature can be calculated from equation (15). Fig. 17 shows that the instantaneous hottest-spot temperature which calculated from (16). 


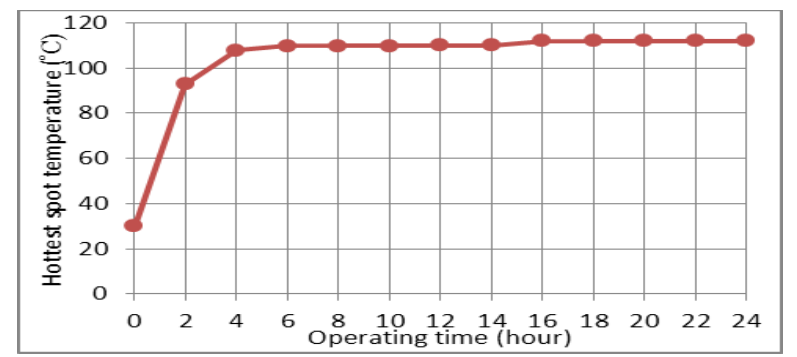

Figure 17: Instantane ous hottest-s pot temperature rise versus time

After calculated hottest-spot temperature, the life reduction and real life of transformer can be expressed as equations (17) and (18).

\section{So, real life $=16.82$ years}

The aging acceleration factor for a given load and temperature or for a changing load and temperature profile over a 24 hours period, as equation (19), and the instantaneous aging acceleration factor can be noticed from Fig. 18.

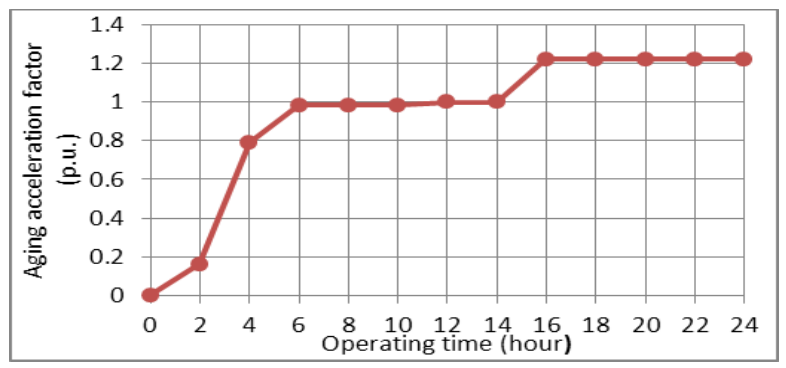

Figure 18: Instantane ous aging acceleration factor rise versus time

Due to insulation aging is accumulative process, thus the equivalent aging acceleration factor can be expressed as equation (20). The percent loss of life can be calculated form equation (21).

The $0.015386 \%$ loss of life occurs per $2.74 * 10^{-3}$ years (24 hours), so the $100 \%$ loss of life will occur after 17.8 years. This result is assured of previous result which it is obtained from equations (17) and (18). Fig. 19 shows the $\%$ loss of life and \% expectancy of life for 24 hours.

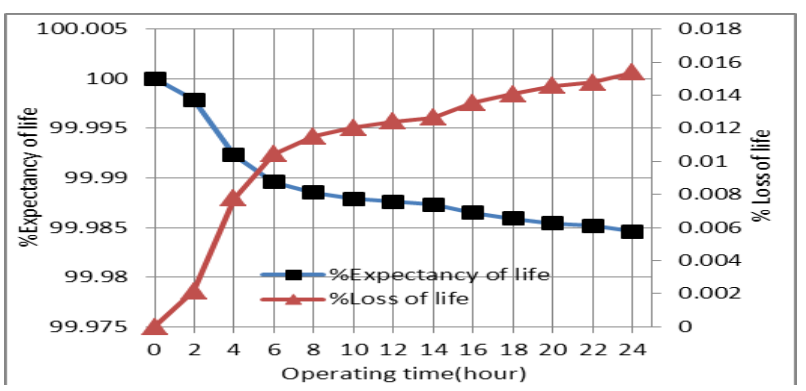

Figure 19: Instantane ous loss of life and expectancy of life versus time

\section{Conclusions}

This paper demonstrates a methodology of the power harmonics effectiveness on power transformer, and power harmonic mitigation method to keep this power transformer in service longer time. This research also helps for concluding predicted and unpredicted very serious points. The power harmonics in this research works to increase of a capacitive current, there fore the probability for appearing load as a capacitive load was so close, and distorting the power factor occurs.

The remarkable of increasing of power losses which act as copper losses, hysteres is losses and eddy current losses in power transformer. It is important to mention that the hysteresis losses is bigger than eddy current losses in normal case, and how the harmonics changing this rule to make the eddy current losses is bigger than hysteresis losses.

The harmonic plays also a necessary role for making the hysteresis losses and eddy current losses which known as no load losses in normal case, to contribute with load losses in harmonic case. This increasing of losses may help for mis operating the differential relay of power transformer without exists any failure inside power transformer or differential zone.

The power harmonics not only contributes for emerging over load conditions, and therefore over load occurs in assistant switch gear of power transformer as circuit breakers, current transformers, capacitor banks and ...etc. but also contributes for emerging the over voltage conditions. The presence of harmonic makes a massive increasing of reactive power, apparent power and decreasing of active power compares with the same load in normal case.

The mitigation method by adding a certain filter in network comes to reduce all hazard effects of harmonics, and how this method success to treat the most of problems of power losses, over load conditions, over voltage conditions, expectancy of life, loss of life and mis operation of differential relay of power transformer.

\section{References}

[1] Ling, P. J. A., and Eldridge, C. J., "Designing modern electrical systems with transformers that inherently reduce harmonic distortion in a pc-rich environment", in proceeding of powersmiths international CORP, Canada, 2011.

[2] Chidester, C., "AFDs and their effect on power quality", in proceeding of ISA northern california Section, South Bay, 2003.

[3] Henville, C. F., "Power quality impacts on protective relays-and vice versa", in proceeding of power engineering society summer meeting, Vancouver, 2001.

[4] Jay asinghe, N. R., Lucas, J. R., and Perera, K. B. I. M., "Power system harmonic effects on distribution transformers and new design considerations for $\mathrm{K}$ factor transformers", IEE, p p.2, 2003.

[5] Fouad, A. A., and Anderson, P. M., "Power system control and stability", Galgotia Publications, New Delhi, pp. 3739, 1981.

[6] Moyo, P., "Network planning guideline for shunt capacitors", in proceeding of ESKOM Guide Group Technology, 2011.

[7] Chaturvedi, Mahor, K., A., and Dwivedi, A. D., "Analysis of impact of firing angle on an AC chopper in terms of harmonic distortion \& power factor", International Journal of Scientific Engineering and Technology (IJSET), vol. 1, pp. 120, 2012.

[8] Daut, I., Sy afruddin, H. S., Ali, R., Samila, M., and Haziah, 
H., "The effects of harmonic components on transformer losses of sinusoidal source supplying non-linear loads", American journal of applied sciences, vol. 12, pp. 21,31, 2006.

[9] Farooq, H., Zhou, C., Allan, M., Farrag, M. E., Khan, R. A., and Junaid, M., "Investigating the power quality of an electrical distribution system stressed by non-linear domestic appliances", in proceeding of International Conference on Renewable Energies and Power Quality (ICREPQ'11), Spain, 2011.

[10] An American National Standard, "IEEE recommended practice for establishing transformer capability when supply ing nonsinusoidal load currents", IEEE, pp.3, 1998.

[11] Amrollahi, M. H., and Hassani, S., "Determination losses and estimate life of distribution transformers with three computational, measurement and simulation methods, despite harmonic loads", Renewable Energy and Power Quality Journal (RE\&PQJ), vol. 9, 2011.

[12] Kumar, H., and Sharma, S., "How to minimize iron losses in transformer", International Journal of Scientific Research Engineering \&Technology (IJSRET), vol. 1, pp. 38, 2012.

[13] Rahimpour, E., Christian, J., Feser, K., and Mohseni, H., "Transfer function method to diagnose axial displacement and radial deformation of transformer windings", IEEE transaction on power delivery, vol. 18, pp. 497, 2003.

[14] Rajput, R. K., "A text book of electrical engineering", Laxmi publications, pp. 264, Newdelhi, 2004.

[15] Pop, G. V., Chindri, M., and Gecan, C. O., "Economical implications regarding the operation of power transformers in harmonic polluted power systems", scientific bulletin of the petru maior university of tirgu mures, vol.6, pp. 127, 2009.

[23] Swift, G. W., Zocholl, S. E. and etal., "Adaptive transformer thermal overload protection", IEEE transaction on power delivery, vol. 16, pp. 517, 2001.
[16] Schijndel, A. V., "Validation of reliability forecasting for power transformers", in proceeding of probabilistic methods applied to power systems (PMAPS), rincon, USA, 2008.

[17] Desmet, J., and Delaere, G., "Harmonics selection and rating of transformers", in proceeding of copper development association (CDA), 2005.

[18] Delaiba, A. C., Oliveira, J. C., Vilaca, A. L. A., and Cardoso, J. R., "The effect of harmonics on power transformers loss of life", in proceeding of circuits and Systems, Rio de jan eiro, vol.2, pp. 933 - 936, 1995.

[19] Sadati, S. M. B., Motevali, B. D., Dargahi, M., and Asrami, M. Y., "Evaluation of distribution transformer Losses and remaining life considering network harmonic, based on analytical and simulation methods", Australian Journal of Basic and Applied Sciences (AJBAS), vol. 10, pp. 5295, 2010.

[20] Rajini, V., "Accurate location of transformer hottest spot by FEM and thermal models", International Journal of Computer Applications, vol. 37, pp. 38, 2012.

[21] Asrami, M. Y., Mirzaie, M., Akmal, A. S., and Gholamian, S. A., "Life estimation of distribution transformers under non-linear loads using calculated loss by 2D-FEM", Journal of Electrical Systems (JES), pp. 12-24, 2011.

[22] Srinivasan, M., and Krishnan, A., "Prediction of transformer insulation life with an effect of Environmental variables", International Journal of Computer Applications, vol. 55, pp. 46, 2012. 